\title{
DISAIN APARTEMEN DAN KAWASAN PERUMAHAN YANG MENGEDEPANKAN KESELAMATAN ANAK-ANAK
}

\author{
Nangkuka Utaberta \\ Peneliti di Pusat Kajian Alam Bina Dunia Melayu, Universiti Teknologi Malaysia. \\ Email: nangkula_arch@yahoo.com
}

\begin{abstract}
ABSTRAK
Tulisan ini didasarkan pada pengamatan penulis terkait dengan masalah keselamatan anak-anak di dalam perumahan bertingkat maupun tidak bertingkat. Keselamatan anakanak dimanapun berada menjadi permasalahan pokok yang harus diperhatikan. Anakanak sesuai dengan karakternya belum mempunyai penilaian tentang sesuatu itu membahayakan atau tidak. Dalam konteks rumah tinggal yang berbentuk rumah susun, apartemen ataupun rumah tidak bertingkat, faktor keamanan anak-anak menjadi sangat penting bagi keluarga muda yang mempunyai anak-anak, untuk memilih rumah tinggalnya. Secara arsitektural, faktor keamanan anak-anak ini menjadi bagian dari pemikiran arsitek pada saat mendisain rumah tinggal. Pola tata ruang dan pola penyusunan site plan merupakan salah satu cara yang diputuskan arsitek untuk mewujudkan faktor keamanan terhadap anak-anak. Penulis mengharap bahwa tulisan ini dapat menyadarkan arsitek dan pengembang perumahan untuk lebih sensitif terhadap produk yang dihasilkannya.
\end{abstract}

Kata Kunci: keamanan anak, apartemen, rumah susun.

\section{PENDAHULUAN}

Di tengah pesatnya pembangunan baik di kota besar, kota kecil bahkan perkampungan di Indonesia, masalah kebutuhan akan perumahan merupakan sebuah faktor penting yang tidak dapat diabaikan. Salah seorang rekan saya dari sebuah pusat studi perumahan pemerintah mengatakan bahwa kebutuhan akan rumah di Indonesia mencapai 4-5 juta rumah setiap tahunnya, sementara kemampuan pihak pemerintah maupun swasta untuk memenuhinya tidak mencapai 500.000 per tahun. Namun sayangnya usaha pemenuhan kebutuhan akan perumahan, baik yang dilakukan oleh pemerintah melalui proyek rumah susun dan RSS-nya atau pihak swasta dengan berbagai ide perumahannya seringkali mengabaikan beberapa kebutuhan mendasar yang sangat penting terutama bagi keselamatan anakanak kita. Tulisan ini merupakan suatu bentuk keprihatinan penulis akan kurangnya perhatian dari para arsitek, kontraktor maupun para pengambil kebijakan dalam memperhatikan masalah keselamatan anak, sekaligus sebuah peringatan kepada para orang tua sebagai bagian dari konsumen produk pihak-pihak tersebut agar lebih hatihati dalam memilih produk rumah yang akan mereka gunakan.

Ada dua masalah utama yang akan coba penulis kemukakan berkaitan dengan masalah keselamatan dalam perumahan kita dewasa ini. Yang pertama adalah kurang diperhatikannya pengaman pada bangunan perumahan (rumah susun atau apartemen) yang dirancang bertingkat sehingga banyak menimbulkan kecelakaan (terutama pada anak-anak) dan masalah perancangan perumahan dengan penyusunan rumah serta pola jalan yang membahayakan keselamatan anak-anak kita.

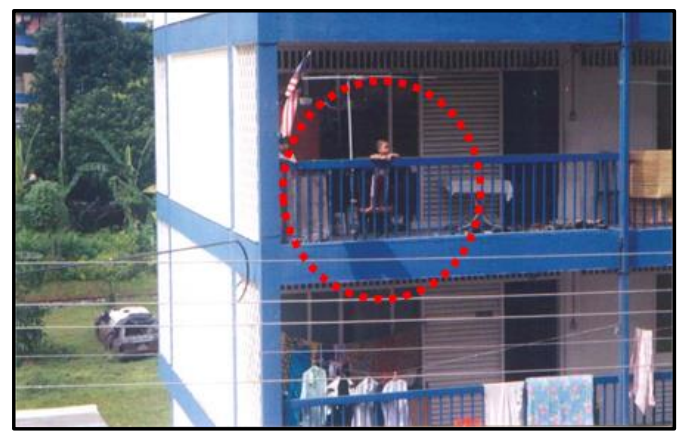

Gambar 1. Desain pagar yang membahayakan anak. Sumber: Survei Lapangan , 2002 


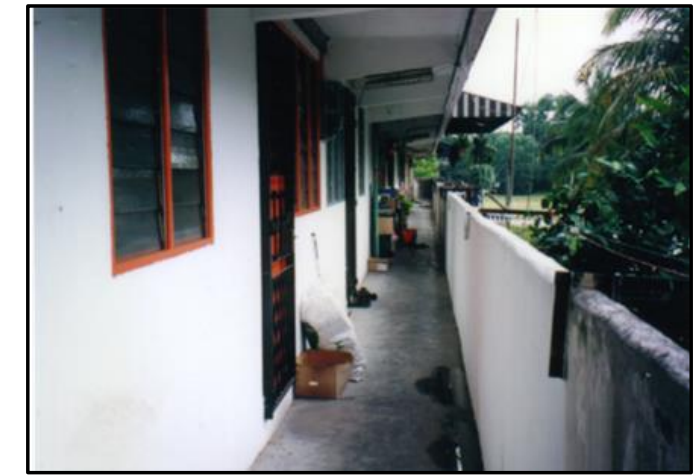

Gambar 2. Kondisi selasar rumah susun yang sempit dan pagar yang terlalu pendek. Sumber: Survei Lapangan, 2002

\section{BAHAYA DI ATAS BANGUNAN BERTINGKAT}

Jika kita lihat perancangan beberapa rumah susun sebagaimana terlihat pada beberapa gambar 3 dan gambar 4 dibawah kita akan melihat sebuah masalah serius baik dari segi perancangan maupun aspek teknisnya. Rumah susun dan apartemen kita merupakan suatu hasil duplikasi dari denah lantainya yang kemudian dicetak dan diangkat keatas, hasilnya adalah sebuah denah lantai yang sama dari lantai ke lantai.

Dalam pembangunan sebuah bangun-an bertingkat, metode ini merupakan suatu hal yang biasa digunakan. Tujuannya jelas untuk mengurangi biaya dan mempermudah pemasangan pendukung teknis bangunan, seperti pipa air, tangga darurat atau sarana pencegah kebakaran. Pada desain awalnya metode ini biasa digunakan pada pembangunan kantor baik swasta maupun pemerintah.

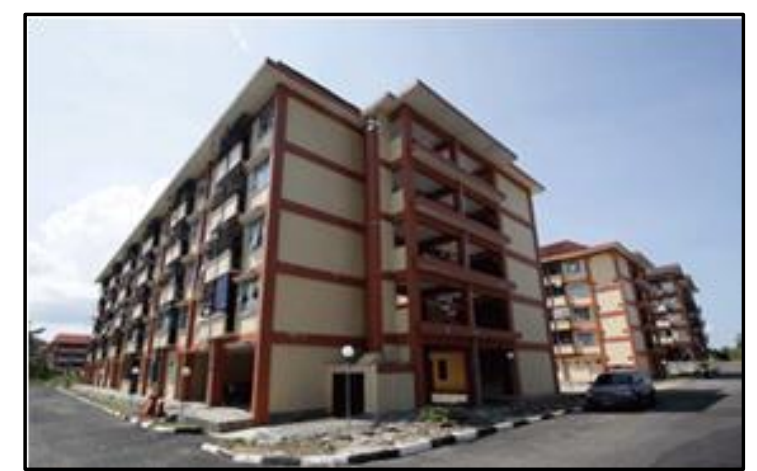

Gambar 3. Beberapa Rumah susun yang seringkali kurang memperhatikan aspek keselamatan bagi anakanak kita.

Sumber: http://batampos.co.id/15-06-2014/pemdadiwajibkan-bikin-perda-rumah-susun/

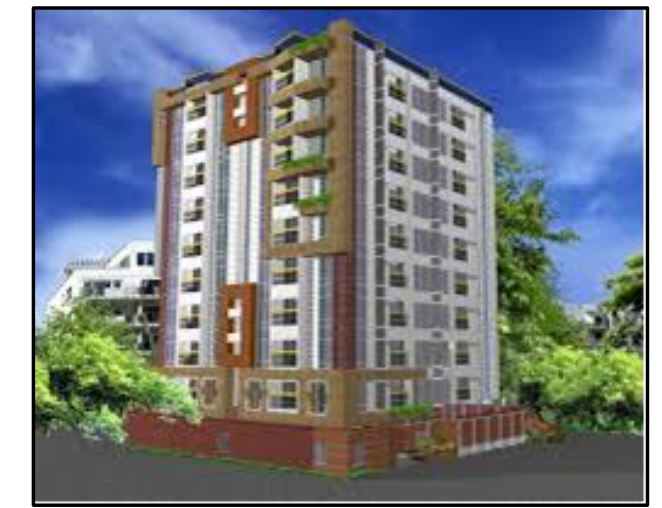

Gambar 4. Beberapa apartemen yang seringkali kurang memperhatikan aspek keselamatan bagi anakanak kita.

Sumber: http://www.365flats.com/resale.php

Metode yang sama juga kemudian diterapkan oleh arsitek dan kontraktor ketika membangun sebuah apartemen dan rumah susun. Masalahnya para arsitek sebagai pihak yang paling bertanggung-jawab melupakan satu faktor utama dari sebuah proses perancangan, yaitu mereka melupakan siapa yang kemudian akan menjadi pengguna dari bangunan tersebut. Mereka melupakan bahwa pada bangunan kantor semua penghuninya adalah orang dewasa yang hanya akan bekerja beberapa jam saja di dalam ruangan, sedangkan apartemen dan rumah susun yang mereka rancang akan ditempati oleh berbagai golongan usia sepanjang hari. Menerapkan metode perancangan sebuah kantor kepada perancangan sebuah apartemen dan rumah susun merupakan sebuah kesalahan besar.

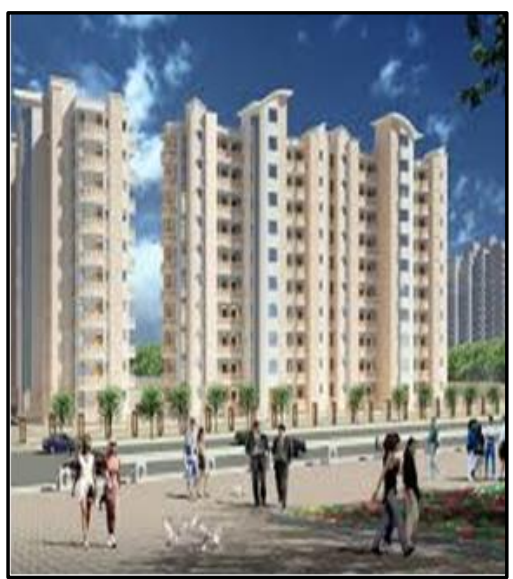

Gambar 5. Bangunan apartemen yang merupakan hasil duplikasi dari denah lantai dasarnya, seharusnya dirancang berbeda.

Sumber: http://www.fastaanytimelock.com/residentialapartment-mohali-punjab-mitula-homes.html 


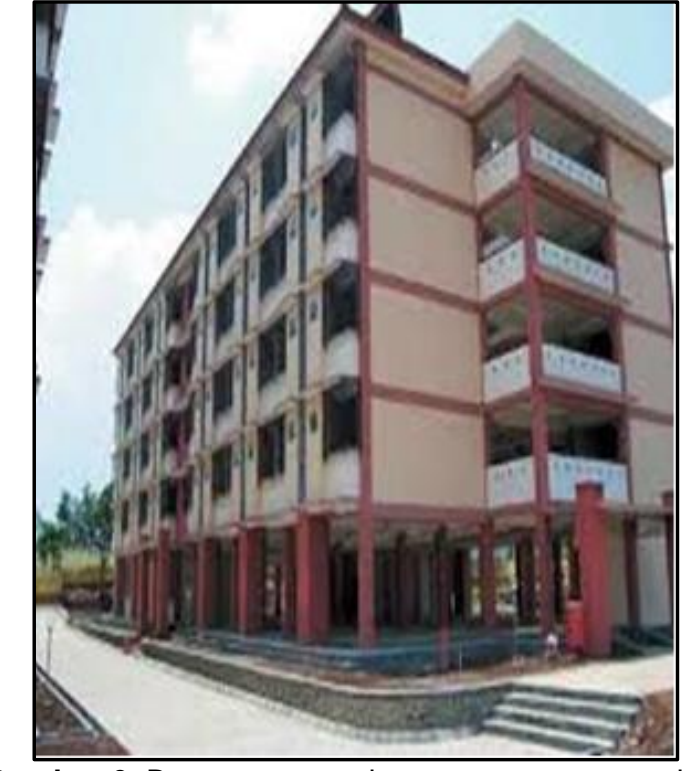

Gambar 6. Bangunan rumah susun yang merupakan hasil duplikasi dari denah lantai dasarnya Sumber : http://pustaka.pu.go.id/new/infrastrukturrumah-susun.asp?start=11

Di kantor bertingkat, orang tidak akan sering membuka jendelanya karena mereka sibuk bekerja. Disamping itu biasanya mereka juga harus menjaga suhu di dalam ruangan tempat mereka kerja yang ber-AC.

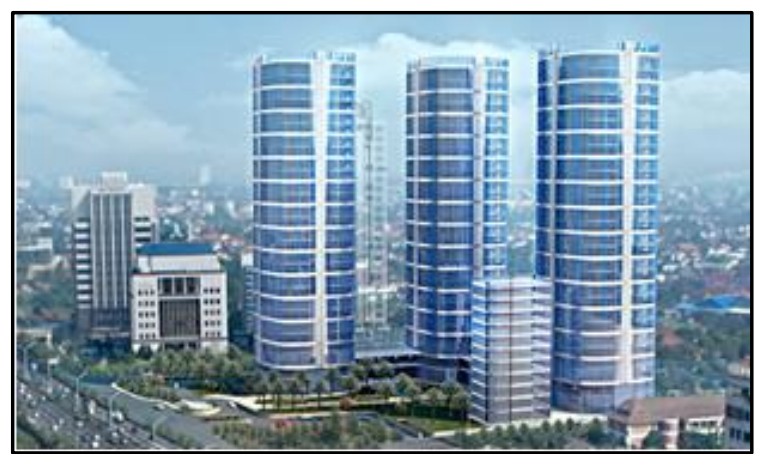

Gambar 7. Bangunan perkantoran yang merupakan hasil duplikasi dari denah lantai dasarnya. Sumber: http://www.housingestate.com/read/2014/01/08/pasok-perkantoran-tbsimatupang-kalahkan-cbd/

Hal yang berbeda terjadi di apartemen dan rumah susun. Disini orang harus keluar dan menyapa tetangganya, anak-anak mereka memerlukan tempat bermain, sang ibu mungkin perlu melihat keluar kalau-kalau ada penjual sayur yang lewat dan seribu satu aktivitas berbeda lainnya.

Pengamanan sederhana dapat dilakukan dengan: melebihkan pelat lantai pada lantai bersangkutan (lebihan lantai ini dapat menjadi penahan matahari pada lantai dibawahnya), membuat tempat tanaman di luar balkon (koridor), dapat juga dilakukan dengan melakukan perbedaan lantai (tidak hanya menduplikasinya sampai atas), atau dengan membuat sebuah jendela yang tidak mudah dicapai oleh anak.
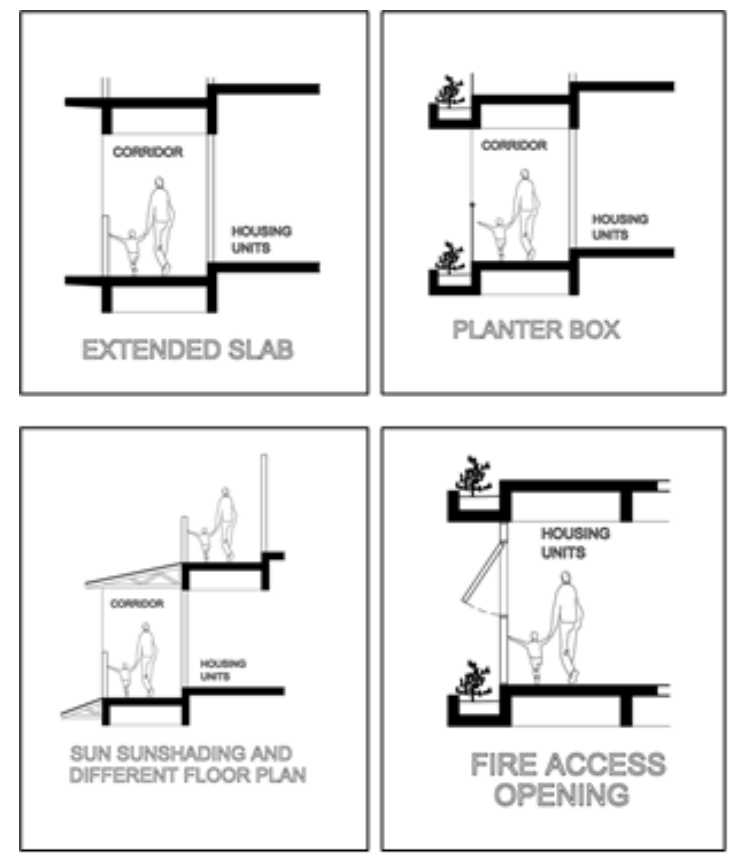

Gambar 8. Pengamanan sederhana pada apartemen Sumber: Analisis penulis

Hal inilah yang kemudian menyebabkan berbagai bentuk, perancangan teras dan koridor pada beberapa apartemen dan rumah susun ini menjadi sebuah medan pertaruhan nyawa bagi anak-anak kita yang tidak tahu apa-apa.Solusi dari masalah ini sebenarnya sederhana, namun dari berbagai perancangan apartemen dan rumah susun yang baru belum mandapat perhatian yang serius.

Pertama, jelas dengan merubah metode perancangannya. Mungkin kita dapat variasi setiap dua lantai dengan memperhatikan aspek keselamatan dengan merancang balkon, koridor dan teras yang tepat. Perubahan metode ini mungkin dapat meningkatkan kualitas dari bangunan kita karena dimungkinkannya penahan cahaya matahari dan bukaan bagi pengaturan suhu udara. Jika kita masih menggunakan metode duplikasi lantai dasar yang diangkat keatas sebagaimana yang saat ini umumnya dilakukan, maka mungkin beberapa tips berikut ini akan sangat berguna. 


\section{Bahaya di depan pintu perumahan anda}

Masalah yang sama juga menimpa perumahan rendah kita. Metode penyusunan rumah dan penempatan jalan yang digunakan memungkinkan sebuah medan maut hanya beberapa meter dari pagar rumah kita.

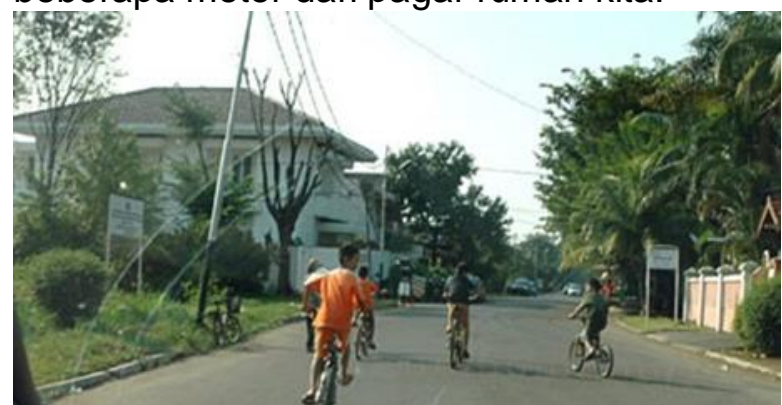

Gambar 9. Tempat bermain anak-anak di jalan yang membahayakan

Sumber :

http://m.autobild.co.id/read/2010/06/11/775/17/6/Santai-

Tapi-Tetap-Waspada

Kita sering mendapati kecelakaankecelakaan di kompleks perumahan (bahkan yang mewah) berupa ditabraknya anak kecil ketika bermain di depan rumahnya. Hal inilah yang kemudian memaksa orang tua harus merelakan anaknya main game seharian di rumah demi menjaganya dari bahaya yang ada di depan rumahnya. Hal ini secara psikologis akan memberi dampak negatif bagi perkembangan mental dan perilaku anak.

Jika kita lihat metode yang umumnya digunakan pada perancangan perumahan kita, dari mulai perumahan sangat sederhana hingga perumahan mewah pun maka kita akan mendapati bahwa metode penyusunan rumah dan jalan yang digunakan adalah metode grid.

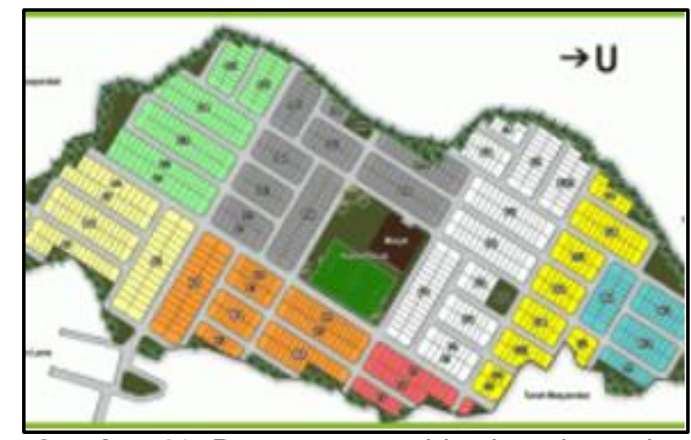

Gambar 10. Penggunaan grid sebagai standar perancangan rumah di Indonesia.

Sumber : http://www.bobaronline.com/2011/11/krisisair-bersih-di-perumahan-griya-salak-endah-ii/

Metode ini digunakan karena ia adalah metode yang paling mudah (penempatan jalan dan fasilitas pendukung rumah lainnya akan lebih sederhana), disamping itu metode ini dipercaya dapat mengoptimalkan pembangunan rumah pada lahan yang ada (dengan metode ini diyakini banyak rumah yang dapat dibangun di lahan tersebut sehingga mendatangkan keuntungan optimal). Namun kesalahan yang sama dilakukan kembali. Arsitek dan developer melupakan aspek utama dalam perancangannya. Mereka melupakan analisa terhadap pihak yang akan menggunakan produk mereka!

Metode grid memaksa jalan kendaraan masuk ke dalam sela-sela bangunan dan mengakibatkan mobil lalu-lalang dengan kecepatan tinggi di depan bangunan. Hal ini seringkali menjadi masalah serius justru pada banyak perumahan mewah yang jalan di depan rumahnya begitu lebar, sementara di perumahan yang lebih sederhana justru tidak terlalu menimbulkan masalah karena jalannya relatif sempit. Hal inilah yang kemudian menyebabkan orang berlomba-lomba membangun polisi tidur di depan rumahnya.

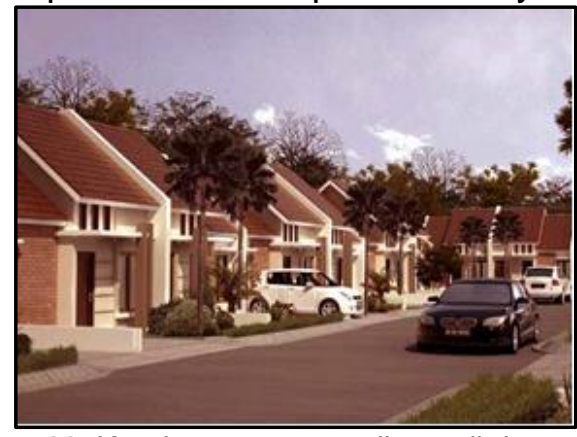

Gambar 11. Kendaraan yang melintas di depan rumah kita, mengancam jiwa anak-anak kita.

Sumber : https://infopeluangusaha.org/wpcontent/uploads/2014/12/usaha-di-komplek perumahan.jpg

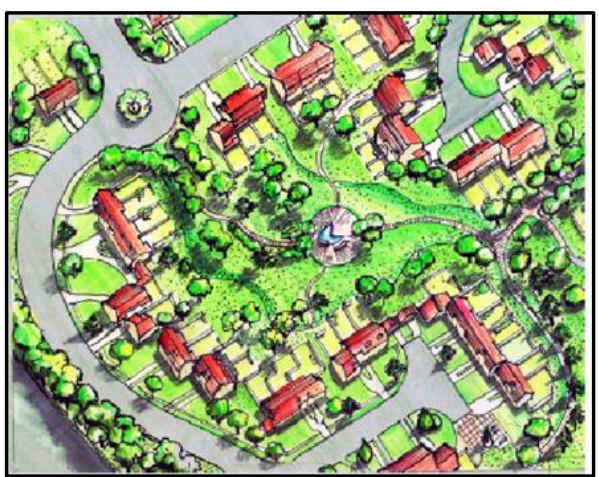

Gambar 12. Perancangan dengan metode kluster Sumber : http://maddysamaddar.com/research/ 
Pembangunan polisi tidur seharusnya menyadarkan arsitek dan pengembang bahwa ada yang salah pada perancangan rumahnya, jika mereka cukup sensitif. Ide dan perancangan rumah (pada gambar 12) menggunakan metode cluster (pengelompokkan) yang kemudian lebih menjamin kemanan bagi anak-anak penghuninya.

Pada perancangan dengan metode cluster ini terlihat bahwa jalur kendaraan (warna kuning) diasingkan dan diletakkan di luar kelompok-kelompok bangunan sehingga memungkinkan zona bebas perlintasan jalan dan jalur bersepeda (warna krem) bagi anakanak kita.

Metode penyusunan rumah dengan sistem cluster ini memungkinkan sebuah pengawasan terbatas terhadap anak-anak kita. Disamping itu perancangan perumahan dengan metode ini memungkinkan sebuah interaksi yang positif antar tetangga.

\section{PENUTUP}

Penulis mengharapkan bahwa tulisan sederhana ini dapat membangkitkan kesadaran dari para arsitek dan pengembang untuk lebih memperhatikan pengguna dari bangunan mereka. Arsitek dan pengembang harus lebih sensitif melihat dampak sosial dari produknya. Tulisan ini juga diharapkan dapat menjadi bahan pertimbangan bagi para pengambil kebijakan di negeri ini dalam menghasilkan standar perancangan yang lebih baik. Akhir sekali penulis juga berharap agar tulisan ini dapat membangkitkan kesadaran dari para pengguna (konsumen), khususnya para orang tua untuk memperjuangkan apa yang seharusnya menjadi hak anak-anak kita! Demi masa depan mereka

\section{DAFTAR PUSTAKA}

http://batampos.co.id/15-06-2014/pemda-diwajibkan-bikin-perda-rumah-susun/

http://www.365flats.com/resale.php

http://www.fastaanytimelock.com/residential-apartment-mohali-punjab-mitula-homes.html

http://pustaka.pu.go.id/new/infrastruktur-rumah-susun.asp?start=11

www.housing-estate.com/read/2014/01/08/pasok-perkantoran-tb-simatupang-kalahkan-cbd/

http://m.autobild.co.id/read/2010/06/11/775/17/6/Santai-Tapi-Tetap-Waspada

http://www.bobaronline.com/2011/11/krisis-air-bersih-di-perumahan-griya-salak-endah-ii/

https://infopeluangusaha.org/wp-content/uploads/2014/12/usaha-di-komplek-perumah

http://maddysamaddar.com/research/ 